\title{
NAKED SUNSPOTS
}

\author{
MARGARET LIGGETT and HAROLD ZIRIN
}

Big Bear Solar Observatory, California Institute of Technology

(Received 28 May; in revised form 9 December, 1982)

\begin{abstract}
Naked sunspots are spots seen in $\mathrm{H} \alpha$ to be devoid of associated plage. In magnetograms and $\mathrm{K}$-line little if any opposite polarity field is found, and in soft X-ray images a blank appears in the region of the spot. In almost all cases studied in which naked spots resulted the spot groups had emerged in unipolar regions of the same polarity as the naked spot. At least half of the naked spots are associated with coronal holes. The naked spots are long-lived and show rotation rates close to the Newton-Nunn curve. Most of the naked spots had bright rims in $\mathrm{H} \alpha$, and the one spot observed to disappear left no trace in the background magnetic field. These spots may be a means by which separation of $p$ from $f$ magnetic polarity occurs.
\end{abstract}

\section{Introduction}

Large sunspot groups decay in two modes: most leave behind diffuse bipolar plage, while in about a third of the groups with a large dominant symmetric $p$ spot the plage of both polarities weakens and a naked sunspot remains, usually immersed in a less concentrated unipolar region of like polarity. These remnant spots are readily recognized in $\mathrm{H} \alpha$ because all the other spots on the Sun are associated with plage. Naked sunspots are generally small, far from any $\mathrm{H} \alpha$ plage or the opposite magnetic polarity and often surrounded by a penumbra which is bright in $\mathrm{H} \alpha$. There may be weak plage of like polarity nearby, and sometimes a ring of weak K-line plage appears just around the penumbra. The naked spots must be connected to opposite magnetic field somewhere, but the conjugate fields are not apparent in either magnetograms or $\mathrm{H} \alpha$. We do not have sufficient coverage of the lifetime of the active regions to see where the opposite polarity has gone.

\section{General Properties}

We reviewed full disk $\mathrm{H} \alpha$ data obtained at Big Bear or Caltech and found 21 naked sunspots occurring during a 30 month period from January 1979 to June 1981. The spots, picked by the absence of nearby $\mathrm{H} \alpha$ plage, are listed in Table $\mathrm{I}$, along with two others where we had high resolution data (Mt. Wilson 19270 and 22906). We required the spot to be least 15000 kilometers from the nearest plage of opposite polarity and present for at least three or four days. Once the naked sunspot had been identified, the region was followed during its entire accessible lifetime on the full disk patrol. KPNO magnetograms and synoptic magnetic and $\lambda 10830$ maps of the regions were also examined. A few were found to be not truly naked, and are so noted in Table I. Our sample showed the following properties: 


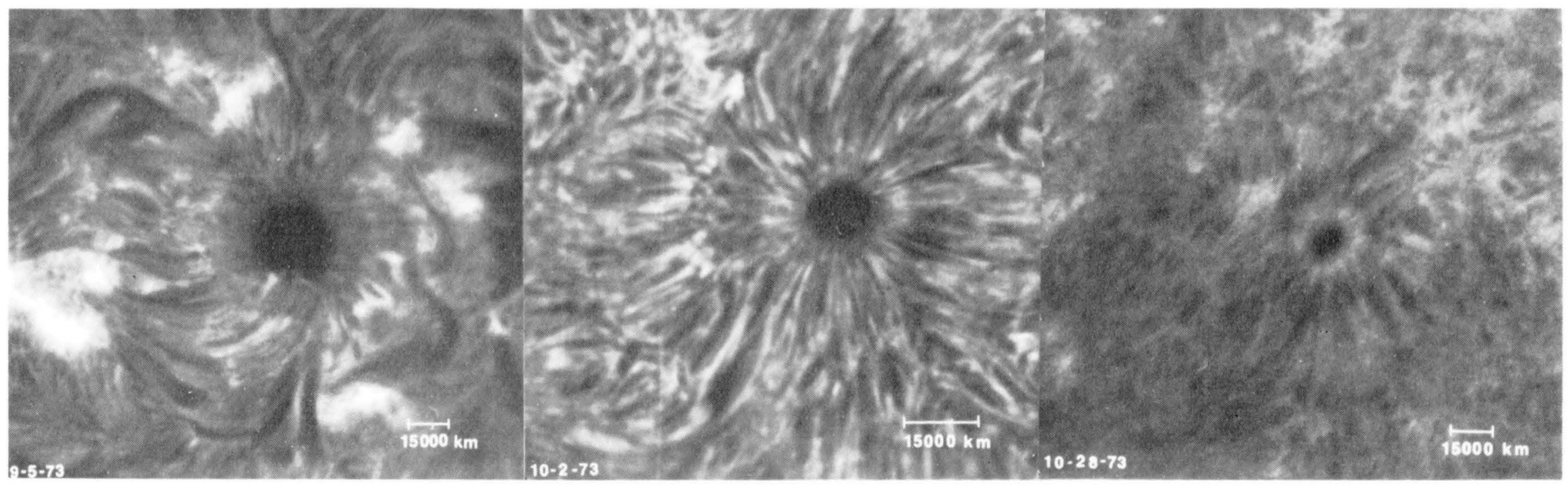

Fig. 1. The evolution of Mt. Wilson 19249-19270-19281 through 3 rotations. (Note that the scales are different, the first and last being from the full disk patrol.) The second and third frames clearly show the bright penumbra as well as the radial fibrils marking field lines connecting to distant fields. 
TABLE I

Characteristics of naked spots

\begin{tabular}{|c|c|c|c|c|c|c|c|}
\hline Month/CMP/Year ${ }^{1}$ & Region $^{2}$ & Mt. W. ${ }^{3}$ & $\begin{array}{l}\text { Life- } \\
\text { time } \\
\text { (days) }\end{array}$ & $\begin{array}{l}\text { Dev. } \\
\text { rot. } \\
\text { rate }\end{array}$ & $\begin{array}{l}\text { No. } \\
\text { days } \\
\text { naked }\end{array}$ & $\begin{array}{l}\text { Bright } \\
\text { penumbra }\end{array}$ & Comments \\
\hline $9 / 3.8 / 73$ & 12543 & 19270 & $50^{++}$ & & 8 & $\mathrm{Y}$ & $\begin{array}{l}\text { returned for } 2 \text { nd rot- } \\
\text { ation with naked spot } \\
\text { ( } 19281) \text { which died on } \\
\text { disc }\end{array}$ \\
\hline $2 / 25.1 / 79$ & 15838 & 20464 & $50^{++}$ & & 5 & $\mathrm{Y}$ & died on back \\
\hline $4 / 23.3 / 79$ & 15955 & 20562 & $50^{++}$ & & 5 & $\mathrm{Y}$ & $\begin{array}{l}\text { plage of AR returned } \\
\text { not truly naked }\end{array}$ \\
\hline $7 / 27.6 / 79$ & 16167 & 20765 & $50^{++}$ & -0.14 & 3 & $\mathrm{Y}$ & plage region returned \\
\hline $8 / 21.2 / 79$ & 16232 & 20817 & $9^{+}$ & & 7 & $\mathbf{N}$ & spot disappeared on disk \\
\hline $9 / 22.3 / 79$ & 16300 & 20898 & $8^{+}$ & & 2 & $\mathrm{Y}$ & $\begin{array}{l}\text { spot disappeared on disk } \\
\text { not truly naked }\end{array}$ \\
\hline $12 / 8.9 / 79$ & 16479 & 21105 & $37^{+}$ & -0.24 & 7 & $\mathrm{Y}$ & died on back \\
\hline $3 / 28.2 / 80$ & 16733 & 21337 & $13^{++}$ & & 3 & $\mathrm{Y}$ & weak plage returned** \\
\hline $4 / 4.1 / 80$ & 16744 & 21350 & $50^{++}$ & -0.15 & 3 & $\mathrm{Y}$ & died on back \\
\hline $5 / 31.7 / 80$ & 16868 & 21479 & 72 & -0.14 & 9 & $\mathrm{Y}$ & died on back \\
\hline $6 / 3.3 / 80$ & 16873 & 21483 & $13^{++}$ & & 6 & $\mathbf{N}$ & weak plage returned** \\
\hline $6 / 4.2 / 80$ & 16875 & 21488 & $35^{+}$ & & 5 & $\mathbf{N}$ & died on back \\
\hline $7 / 11.9 / 80$ & 16970 & 21577 & $50^{++}$ & 0.24 & 3 & $\mathrm{Y}$ & died on back \\
\hline $8 / 11.4 / 80$ & 17040 & 21640 & $13^{++}$ & -0.17 & 2 & $\mathrm{Y}$ & died on back \\
\hline $9 / 26.3 / 80$ & 17163 & 21764 & $50^{++}$ & 0.02 & 5 & $\mathbf{N}$ & died on back \\
\hline $9 / 29.5 / 80$ & 17169 & 21770 & $50^{++}$ & -0.22 & 6 & $\mathrm{Y}$ & plage returned** \\
\hline $10 / 8.0 / 80$ & 17179 & 21793 & $13^{++}$ & & 5 & $\mathrm{Y}$ & died on back \\
\hline $10 / 15.1 / 80$ & 17199 & 21819 & $11^{+}$ & & 4 & $Y$ & $\begin{array}{l}\text { spot disappeared on disk } \\
\text { not truly naked }\end{array}$ \\
\hline $3 / 5.6 / 81$ & 17494 & 22102 & $13^{++}$ & & 3 & $\mathbf{N}$ & died on back \\
\hline $5 / 4.1 / 81$ & 17619 & 22246 & $13^{++}$ & & 4 & $\mathrm{Y}$ & plage returned** \\
\hline $5 / 14.2 / 81$ & 17641 & 22272 & $50^{++}$ & -0.20 & 4 & $\mathrm{Y}$ & died on back \\
\hline $7 / 22.1 / 81$ & 17750 & 22406 & $13^{++}$ & & 5 & $\mathrm{~N}$ & died on back \\
\hline $1 / 8.9 / 82$ & 18123 & 22906 & $50^{++}$ & & 13 & $\mathrm{~N}$ & died on back \\
\hline
\end{tabular}

$+\quad=$ Unknown days on back from one limb.

$++=$ Unknown days on back from both limbs.

** $=$ Spots present but unrelated to naked spot.

1 = Central meridian passage of naked spot.

2 = Hale, McMath or Big Bear region number.

$3=$ Mt. Wilson spot number.

\section{A. ORIGINS}

$75 \%$ of the naked sunspots represented the return of large dominant $p$ spots which had been part of large active regions during previous rotations. These spots had been somewhat isolated from the main plage with which they were associated.

Most naked sunspots then appear to be the remnants of large spots associated with substantial active regions where the following plage was somewhat separated from the spot and died sooner than the sunspot. To determine if this was a normal decay process 
of large spots a survey of four months each of the years 1969-81 was carried out. It showed that $35 \%$ of the spots with areas greater than 400 millionths of the visible hemisphere evolved into naked spots. There was no dependence of this fraction on the phase of the sunspot cycle.

The remaining $25 \%$ of our sample appeared naked during their first rotation. They all rotated onto the disk as single spots $(\alpha p)$ with plage and lost the plage during disk transit. These spots were all smaller than 400 millionths of the visible hemisphere.

With two exceptions all of the naked sunspots were of $p$ polarity. About $2 / 3$ of the naked sunspots emerged, and were immersed in, an extensive region of the same polarity. In an effort to determine if the polarity of the surrounding area is a governing factor in naked spot development we surveyed nine months of full disc magnetograms and found 18 normal active regions where the surounding polarity could be clearly established. We noted 11 immersed in $p$ flux and 7 , in $f$ flux. Of the eleven associated with $p$ flux, $18 \%$ were naked on the next rotation and the remainder showed only plage or had disappeared. None of the active regions immersed in $f$ flux evolved as naked spots. We are reasonably convinced that dipole emergence in a unipolar region of the same polarity as the preceding spot contributes to the naked spot syndrome, the background flux cancelling the $f$ flux.

\section{B. Penumbra}

$85 \%$ of returning naked spots had a bright penumbra (see Figure 1). Only one of the first rotation naked spots showed a bright penumbra. The brightening seemed particularly evident when the spot was declining.

\section{Longevity}

The average lifetime of our sample was relatively high, $>32$ days. (Obviously the number of days of existence on the back side of the Sun is unknown.) Since most naked spots are clearly identifiable returning spots they can be used to measure solar rotation without the errors arising from changes in the active region. We measured the rotation rate for the naked spots in our study and give in Table $I$ the deviation (which is quite small) in rotation period from the Newton and Nunn (1951) period for the latitude of the spot.

\section{The magnetic PiCture}

Although the appearance of naked spots in $\mathrm{H} \alpha$ is quite distinct, more sensitive indicators such as $\mathrm{K}$-line spectroheliograms or magnetograms show a more complicated situation. In Figure 3 we see that quite close to the spot there is a ring of weak opposite polarity which is reflected in $\mathrm{K}$-line emission but does not appear in $\mathrm{H} \alpha$ (the brighter plages match perfectly in all three wavelengths). In other cases scattered areas of weak opposite polarity are found near the naked spot. These fields are far weaker than the spot fields which must therefore connect to distant fields. 

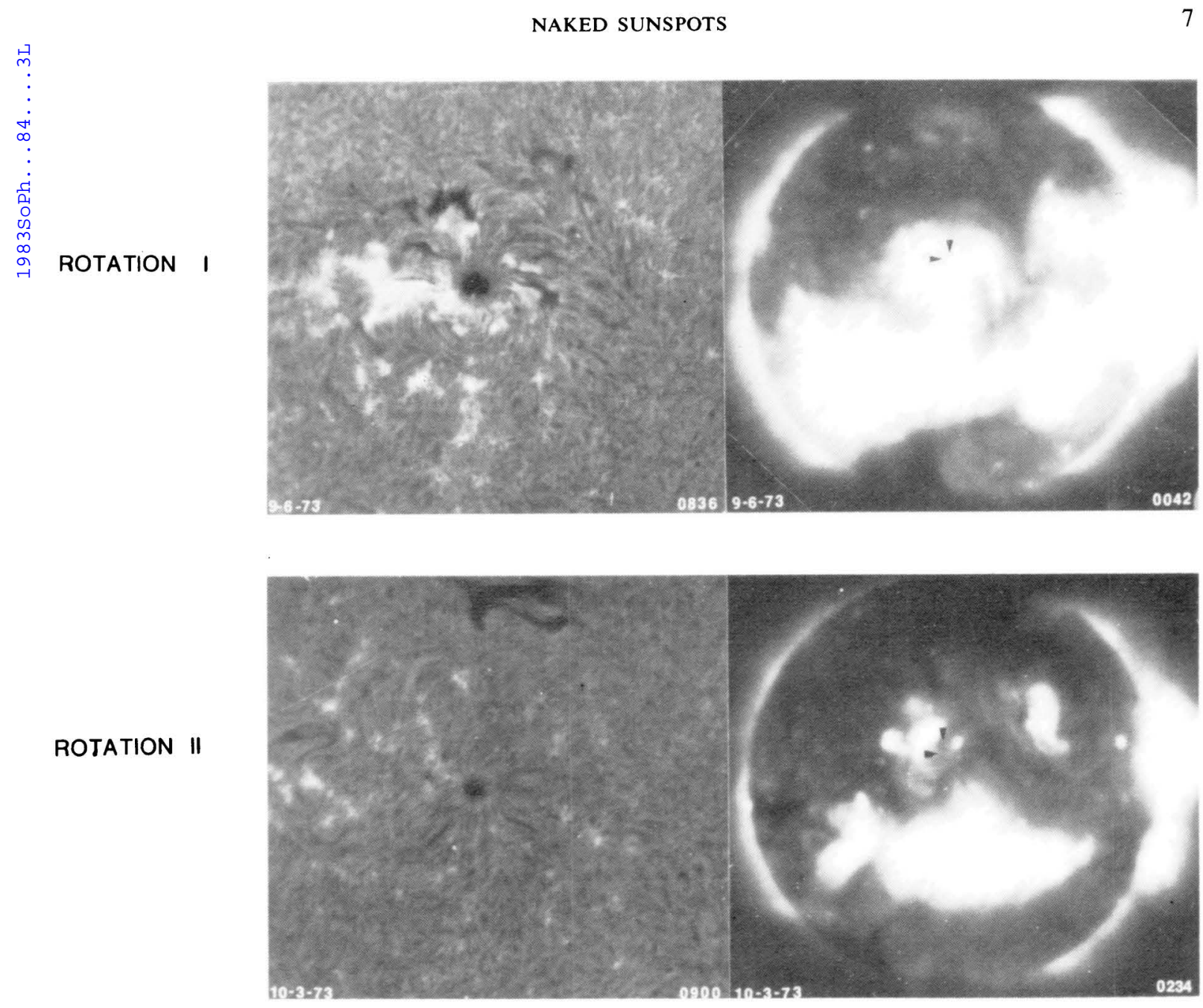

ROTATION III

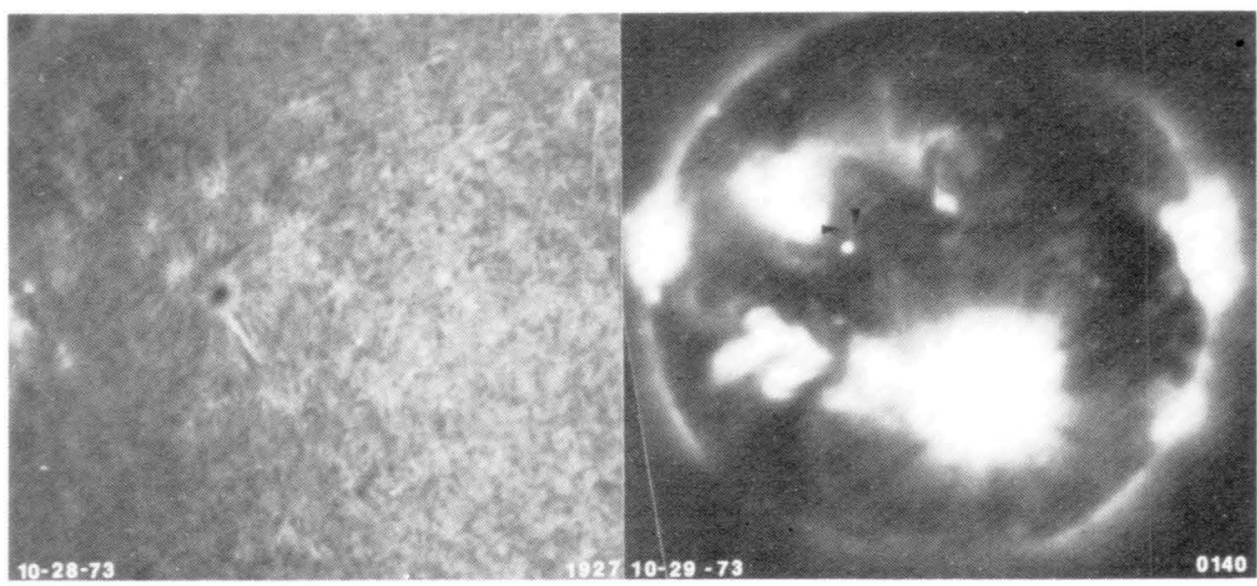

Fig. 2. $\mathrm{H} \alpha$ (left) and X-ray images (AS\&E Skylab frames) of the same spot as shown in Figure 1. The $\mathrm{H} \alpha$ images cover $7^{\prime} \times 7^{\prime}$, roughly $1 / 4$ of the solar diameter in each direction. The position of the spot is marked on the X-ray frames. There is no X-ray emission from the spot after it becomes naked. The bright spots nearby are ephemeral regions.

The magnetic field strength of the spot in Figure 3 measured at Mt. Wilson was exceptionally high ( $5000 \mathrm{G}$, John Adkins, private communication). Mt. Wilson field values for the other naked spots in our survey were found to be average, 1600 to $2200 \mathrm{G}$. 


\section{JANUARY 1982}

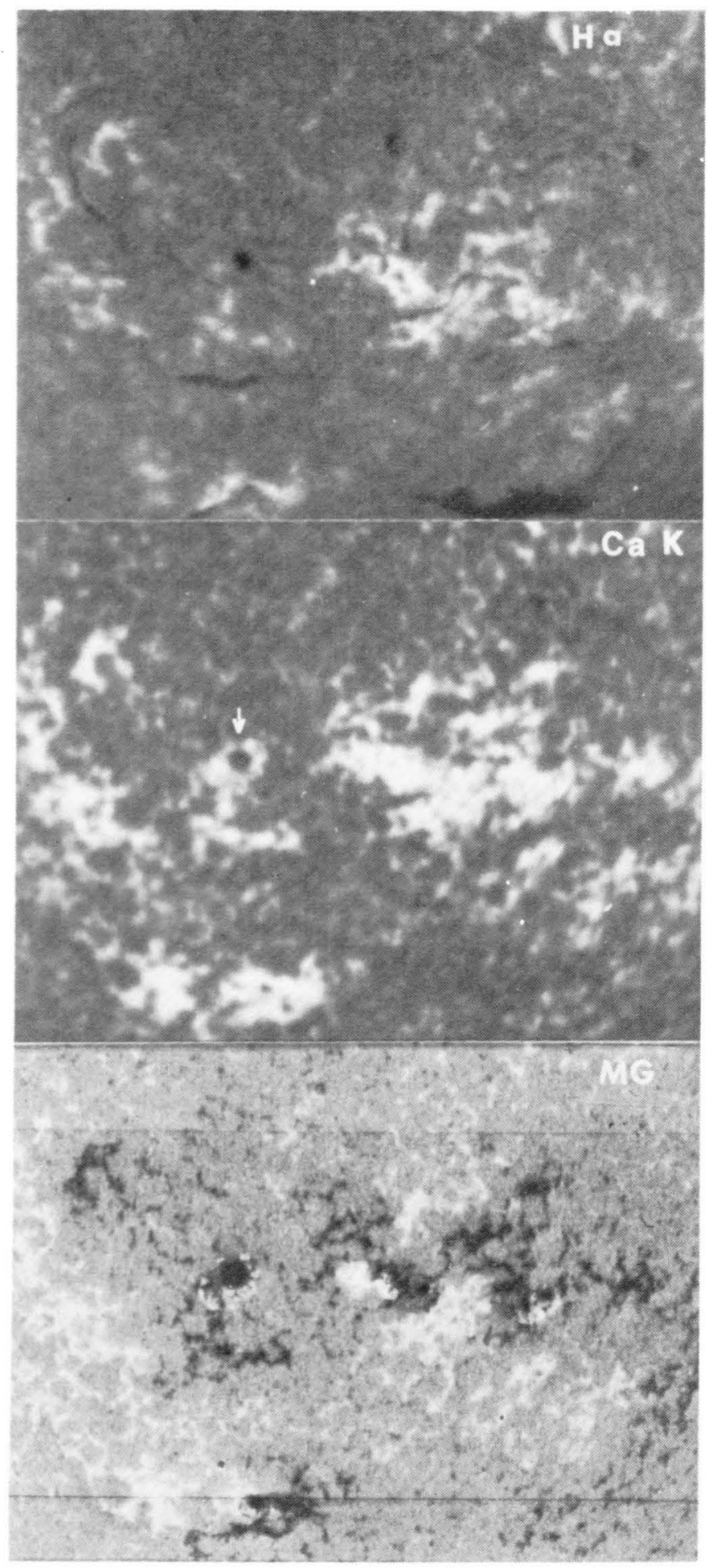

Fig. 3. Portions of full-disc $\mathrm{H} \alpha$ filtergram, K-line spectroheliogram (SPO) and magnetogram (KPNO) of Mt. Wilson 22906. The $\mathrm{H} \alpha$ photo illustrates a typical naked spot devoid of associated plage. The magnetogram and K-lines show a weak opposite field region in the 'superpenumbra'. Otherwise this naked spot is completely surrounded by $p$ polarity. 


\section{E. X-RAY APPEARANCE}

It is known (Webb and Zirin, 1980) that sunspots are dark in X-ray, but bright X-rays are seen from associated coronal condensations where hot material is trapped in the closed fields. Skylab X-ray photos available for the September, 1973 spot (Figure 2) show that the naked spot had no associated coronal condensation. This confirms our idea that the spots must be connected to distant diffuse fields and neither trapping nor heating of the coronal material takes place.

F. $\lambda 10830$

Since naked spots have no associated coronal condensation they should not show $\lambda 10830$ absorption and this is what we found on the KPNO $\lambda 10830$ spectroheliograms. All but one of the naked spots had little or no overlying $\lambda 10830$ absorption and at least half were associated with coronal holes picked out from the $\lambda 10830$ maps. A notable example was Mt. Wilson 21819. This spot had been identified as naked in $\mathrm{H} \alpha$, but magnetograph data showed it to be a normal bipolar group. It was in fact marked by $\lambda 10830$ absorption, but surrounded by a large coronal hole. The open field lines associated with the hole may be what gave the region its naked appearance in $H \alpha$.

\section{G. DECAY}

Wallenhorst and Howard (1982) and Wallenhorst and Topka (1982) found that a dying sunspot does not turn into a remnant plage. For a naked spot this effect is particularly clear, as there is no plage to confuse the issue. The decay of Mt. Wilson 21105 (Hale 16479) illustrates the process. The disappearance of the spot in white light (Big Bear) and K-line (Mt. Wilson) is shown in Figure 4. No $\mathrm{H} \alpha$ plage replaced it, nor $\mathrm{K}$-line plage, even though that line is quite sensitive. Sunspot disappearance takes place in ways that are not yet understood. Since most large active regions leave remnant plage, we surmise that it is the plage and not the sunspot that leaves the remnant.

A typical example of the evolution of an active region into a naked spot is Mt. Wilson 19249 (Figures 1 and 2), for which we have high resolution $\mathrm{H} \alpha$ data and Skylab X-ray pictures in September and October, 1973. The region (McMath 12510) arose on the back side of the Sun and first was visible on August 30,1973, displaying a normal amount of plage. Magnetograms show a typical bipolar region. On Skylab X-ray data a moderate-sized, bright coronal condensation is evident.

During its second transit the spot (now Mt. Wilson 12510, McMath 12542) was the largest on the disk but was already naked, with a bright penumbral rim. The magnetograms show only preceding polarity in the general area. In Figure 2 the $\mathrm{H} \alpha$ appearance is compared with the AS\&E X-ray image, which shows no enhancement whatever at or near the spot. The closest X-ray enhancement corresponds to an ephemeral active region more than $28000 \mathrm{~km}$ away.

The spot returned a third time (Mt. Wilson 19281, McMath 12585), greatly reduced in size. It was naked and bright-rimmed throughout this transit, with only $p$ flux in the region surrounding the spot. The Skylab X-ray photos again show no coronal brightening near the spot. 


\section{MT. WILSON 21106}

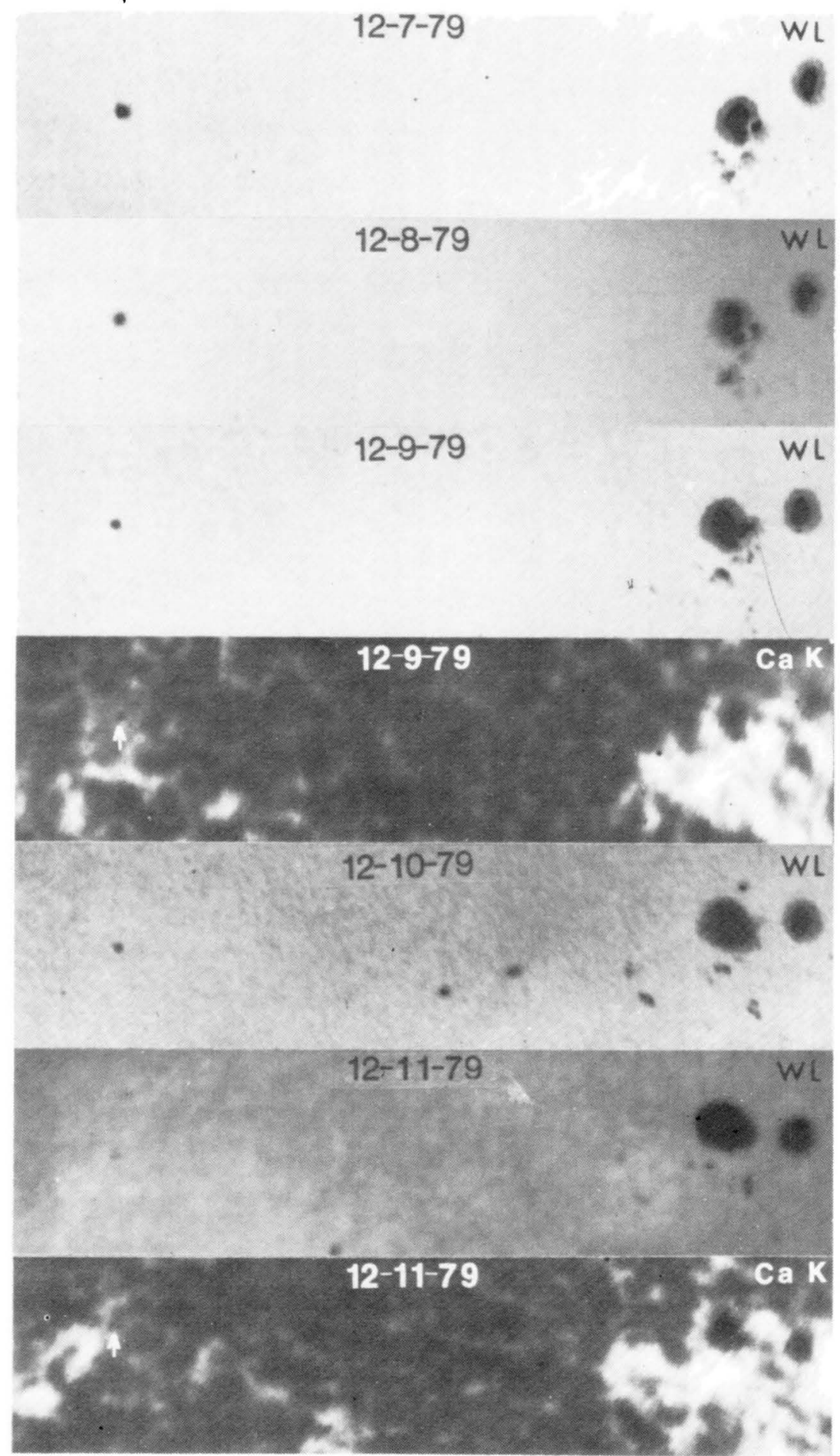

Fig. 4. The disappearance of Mt. Wilson 21106 (left side) recorded in white light at BBSO and on Mt. Wilson's K-line spectroheliograph. Note in the K-line that although the nearby plage is somewhat brighter after the spot disappears on the 11th, no remnant plage appears where the spot was; the fields are gone. 


\section{Discussion}

Naked spots are an important mode of sunspot evolution. Their long life is probably connected with their emergence in regions of the same magnetic polarity, leading to reconnection of the following plage. This condition is not sufficient; the $p$ spot must be large and somewhat detached from the rest of the active region, and no substantial new flux should emerge near the spot. Other conditions may also be necessary; many large spots arise on the sun and less than half of them end up as naked sunspots.

Most solar active regions die away leaving a bipolar plage which has little more polarity separation than the original active region. In the naked spots the separation becomes substantial (but no obvious separation in latitude occurs). The connection to distant fields is mirrored in the extended penumbral fibrils which the naked spots show in $\mathrm{H} \alpha$. Polarity separation in naked spots may play an important role in the evolution of solar magnetic fields. Theories of the sunspot cycle require some mechanism to separate opposite magnetic polarities and eventually produce the polar field. Leighton (1969), for example, suggested a random walk of fields, using the empirical tilt of the magnetic axis of solar active regions to separate the fields. But Mosher (1977) and Prata (1973) both show that the weak fields around spots diffuse slowly if at all. In the case of naked spots where bipolar regions emerge in $p$ background, the cancelation of the following polarity against the background field leads to a 'leap-frog' process similar to that discussed by Marsh (1978) by which opposite polarities move further and further apart.

The bright penumbrae are an interesting feature of these spots. Since it seems most obvious when the spot is declining it may be connected with energy dissipation in the break-up.

\section{Acknowledgements}

We are indebted to Dr J. W. Harvey (KPNO) for patiently helping us to go through his data, and to Drs R. Howard (Mt. Wilson), A. Krieger (AS\&E), and J. B. Zirker (SPO) for furnishing their data. This work was supported by AFOSR under grant 82-0018, by the NSF Solar Terrestrial Program under grant ATM-8112698 and by NASA under NGL 05-002-034.

\section{References}

Leighton, R. B.: 1969, Astrophys. J. 156, 1.

Marsh, K. A.: 1978, Solar Phys. 59, 105.

Mosher, J. M.: 1977, Thesis, California Institute of Technology.

Newton, H. W. and Nunn, M. L.: 1951, Monthly Notices Roy. Astron. Soc. 111, 413.

Prata, S. W.: 1973, Solar Phys. 33, 119.

Wallenhorst, S. G. and Howard, R.: 1982, Solar Phys. 76, 203.

Wallenhorst, S. G. and Topka, K. P.: 1982, Solar Phys. 81, 33.

Webb, D. F. and Zirin, H.: 1981, Solar Phys. 69, 99. 